\title{
Successful total en bloc spondylectomy of the L3 vertebra with a paravertebral giant cell tumor following preoperative treatment with denosumab: a case report
}

Hideyuki Kinoshita ${ }^{1,3^{*}}$, Sumihisa Orita ${ }^{1}$, Tsukasa Yonemoto ${ }^{3}$, Takeshi Ishii ${ }^{3}$, Shintaro Iwata ${ }^{4}$, Hiroto Kamoda ${ }^{3}$, Toshinori Tsukanishi, ${ }^{3,5}$, Kazuhide Inage ${ }^{1}$, Koki Abe ${ }^{1}$, Masahiro Inoue ${ }^{1}$, Masaki Norimoto ${ }^{1}$, Tomotaka Umimura ${ }^{1}$, Kazuki Fujimoto ${ }^{2}$, Yasuhiro Shiga ${ }^{1}$, Hirohito Kanamoto ${ }^{1}$, Takeo Furuya ${ }^{1}$, Kazuhisa Takahashi ${ }^{1}$ and Seiji Ohtori ${ }^{1}$

\begin{abstract}
Background: Giant cell tumor is known to be a benign neoplasm that arises most commonly in the long bones, while cases in the spine are rare. Recently, denosumab, a monoclonal antibody that inhibits receptor activator of nuclear factor-kappa $\beta$ ligand, has been used to treat patients with giant cell tumor. However, there are few reports of total en bloc spondylectomy being used for paravertebral giant cell tumor lesions following denosumab therapy.

Case presentation: Our patient was a 20-year-old Japanese woman with a 4-month history of lower back pain. A spinal computed tomography scan and magnetic resonance imaging of her lumbar spine revealed an osteolytic lesion involving the $\mathrm{L} 3$ vertebral body, and the tumor extended toward the left side of the paravertebral soft tissue and into the left pedicle. The lesion was diagnosed as a giant cell tumor by needle biopsy. Denosumab treatment calcified the paravertebral giant cell tumor lesion and the tumor vertebral body was removed completely by total en bloc spondylectomy.
\end{abstract}

Conclusion: This case report describes a patient with a paravertebral giant cell tumor who was successfully treated by preoperative denosumab injection followed by total en bloc spondylectomy.

Keywords: Giant cell tumor, Denosumab, Total en bloc spondylectomy, Paravertebral lesion

\section{Background}

Giant cell tumors (GCTs) account for $4-8 \%$ of all primary bone tumors, and they are most frequently located in the juxta-articular metaphysis of the long bones [1], while $2-3 \%$ of GCTs develop in the spine and sacrum [2]. Denosumab, a monoclonal antibody that inhibits receptor activator of nuclear factor-kappa $\beta$ ligand (RANKL), is used in patients with GCT, inhibiting osteoclast-like giant cell recruitment, thereby preventing the osteolysis typical of GCT [3]. Treatments for GCT depend on its location; excision and intralesional

\footnotetext{
* Correspondence: kinoshi1783@yahoo.co.jp

'Department of Orthopaedic Surgery, Graduate School of Medicine, Chiba University, 1-8-1, Inohana, Chuo-ku, Chiba 260-8670, Japan

${ }^{3}$ Department of Orthopedic Surgery, Chiba Cancer Center, 666-2 Nitonacho,

Chuo-ku, Chiba 260-8717, Japan

Full list of author information is available at the end of the article
}

curettage are used for GCTs in the extremities, whereas denosumab followed by total en bloc spondylectomy (TES) is used for spinal GCTs. TES may be difficult in some patients, however, because of the fragility or paravertebral location of GCT. This case report describes a patient with a paravertebral GCT who was successfully treated by TES of the L3 vertebra following denosumab therapy.

\section{Case presentation}

A 20-year-old Japanese woman with a 4-month history of severe lower back pain was referred to our out-patient department. She had no history of fever, trauma, weight loss, or previous infection.

Radiographic analysis showed collapse of the left side of the L3 vertebral body and swelling of the iliopsoas 
muscle. Spinal computed tomography $(\mathrm{CT})$ revealed an osteolytic lesion involving the L3 vertebral body and surrounding soft tissue, causing vertebral body collapse (Fig. 1a, b). Magnetic resonance imaging (MRI) of her lumbar spine showed the tumor extending toward the left side of the paravertebral soft tissue and into the left pedicle (Enneking SIII) (Fig. 1c, d). Pathological and immunohistochemical analyses of a needle biopsy specimen showed a GCT with multinucleate giant cells surrounded by neoplastic stromal cells (Fig. 2a). A phase 2 trial showed no adverse effects or complications of denosumab, so she was prescribed six cycles of monthly subcutaneous injections of 120-mg denosumab [4]. Lumbar CT during denosumab treatment showed that the tumor included a paravertebral lesion with progressive calcification (Fig. 2b-d).

Following denosumab treatment, she underwent two-stage (anteroposterior) L3 TES. Stage 1 utilized a posterior approach for resecting the posterior vertebral component; the total operation took 5 hours 16 minutes and the total bleeding was $1520 \mathrm{ml}$. Stage 2 utilized an anterior retroperitoneal approach for resecting the anterior vertebral component followed by intervertebral cage insertion; the total operation took 6 hours 43 minutes, and the total bleeding was $2320 \mathrm{ml}$ (Fig. 3a, b). The day before the second-stage operation, preoperative angiography and segmental artery embolization from L3 to L4 were performed to reduce intraoperative bleeding. The vertebral body was removed completely after the discectomies, and the bilateral psoas muscle was released from the L3 vertebral body (Fig. 3c, d). There were no complications during or after the surgery. She was discharged on the seventh postoperative day, ambulatory and without neurological deficits. Two years after surgery, she has not experienced GCT recurrence or implant failure.

\section{Discussion and conclusions}

GCT, or osteoclastoma, is a relatively common benign bone tumor, usually arising from the metaphysis of long bones and extending into the epiphysis. Spinal GCT is rare, accounting for $<2-3 \%$ of GCTs [5], and its treatment remains challenging. Surgery for GCT traditionally
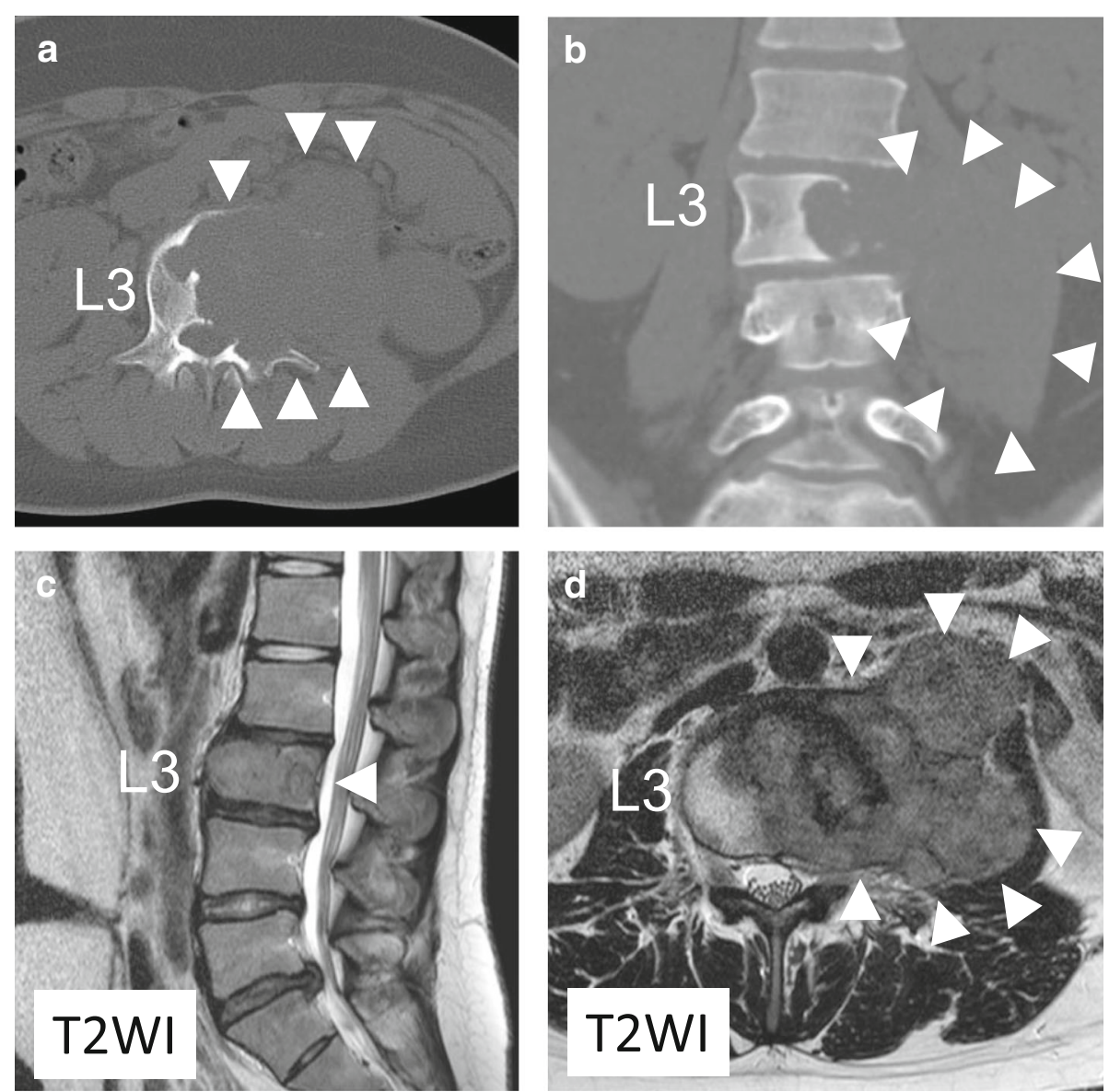

Fig. 1 a, b Computed tomography prior to denosumab treatment, showing an osteolytic lesion involving the L3 vertebral body, which collapsed and expanded into the left side of the iliopsoas muscle (arrowhead). c, d T2-weighted magnetic resonance images prior to denosumab therapy, showing the tumor extending toward the left side of the paravertebral soft tissue (arrowhead). T2WI T2-weighted image 

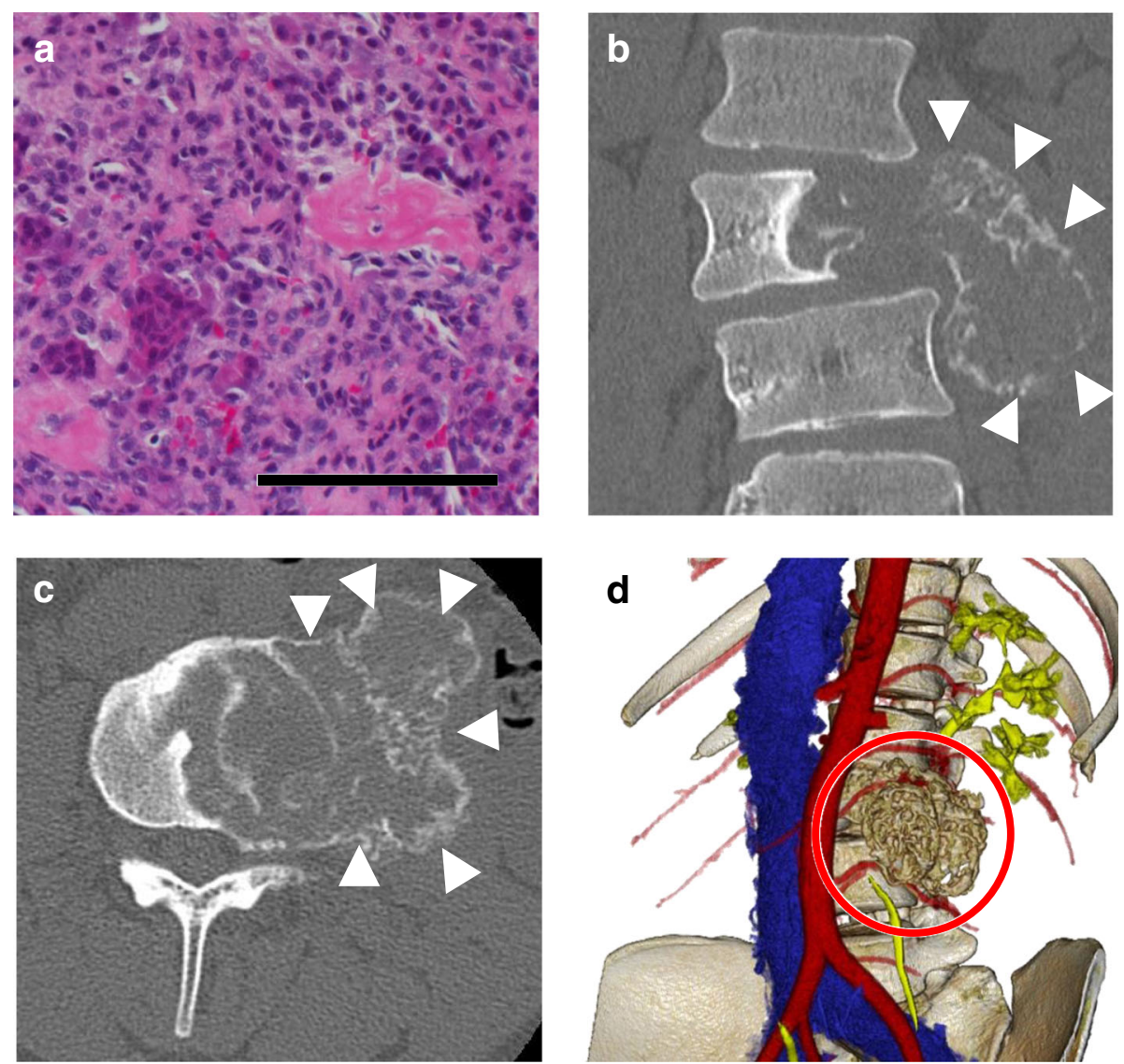

Fig. 2 a Histologic examination of a tumor biopsy specimen prior to denosumab therapy, showing multinucleate giant cells surrounded by neoplastic stromal cells (hematoxylin and eosin staining; scale bar, $100 \mu \mathrm{m}$ ). b-c Computed tomography images after 6 months of denosumab treatment show a clear border between the vertebral tumor body and soft tissue, indicating calcification of the tumor body (arrowhead). $\mathbf{b}$ Coronal view. c Axial view. d Three-dimensional reconstructed image from enhanced computed tomography

consists of intralesional curettage with local adjuvant treatment (for example, polymethylmethacrylate known as PMMA, liquid nitrogen, phenol) or TES, which is effective for lumbar spine tumors without significant risks of neurological deficits or mortality [6, 7]. Optimal TES candidates are patients with Enneking SIII, an aggressive benign spine tumor [8]. Because local recurrence is common following intralesional curettage with adjuvants, reoperation and/or postoperative radiotherapy may be required [9]. In contrast, TES exhibits rarer local recurrence. Local recurrence rates following intralesional curettage and TES are reportedly $50-80 \%$ and $0-15 \%$, respectively [10]. As other studies have reported that TES is effective for thoracic GCT [11, 12], we performed TES for this case of an L3 vertebra with a paravertebral GCT. However, there is no report that TES of huge spinal and paravertebral GCT following preoperative denosumab as in the current case is effective. The current case will be a meaningful report that denosumab is effective even for a huge GCT extending to the soft tissue around the vertebral body.
Denosumab was recently approved for GCT, and for those with severe osteoporosis [13]. Denosumab inhibits the recruitment of osteoclast-like giant cells by neoplastic stromal cells [3], thereby preventing the osteolysis typically seen in GCT. An open-label phase II study (NCT00396279) of denosumab in patients with GCT reported that $86 \%$ had objective responses, that is, elimination of $>90 \%$ giant cells or absence of radiographic progression of the target lesion [14]. Preoperative treatment of our patient with denosumab successfully induced GCT calcification and facilitated TES of the tumor vertebrae. Although denosumab is effective for osteoporosis and GCT, it has side effects of hypocalcemia. Salim et al. reported hypocalcemia in an estimated $8-14 \%$ of the patients treated with denosumab and even more frequently among those with chronic kidney disease (CKD) [15]. To prevent the side effect it is important to assess carefully the vitamin $\mathrm{D}$ status and parathyroid hormone (PTH) status in patients with CKD before denosumab exposure and to closely monitor serum calcium levels subsequently. 

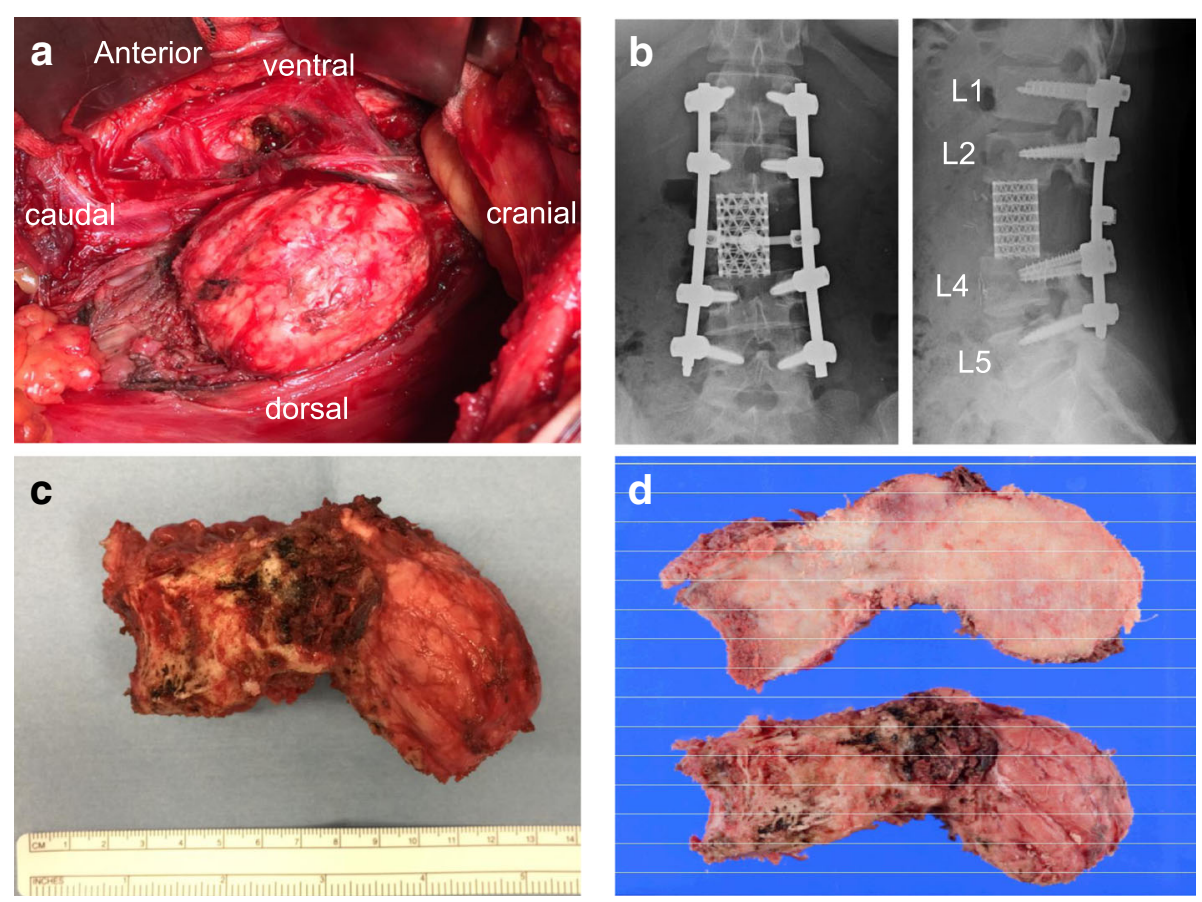

Fig. 3 a Intraoperative examination of the tumor at anterior retroperitoneal approach. $\mathbf{b}$ Plain radiographs of the anteroposterior and lateral view. c, d Results showing that the $L 3$ vertebral tumor body had been completely removed by the anterior transperitoneal approach

The need for postoperative denosumab is still to be determined. Inhibition of RANKL may increase the risk of new malignancies by inducing immunosuppression [16]. Broehm et al. reported two cases of sarcoma that arose from bone GCTs by long-term denosumab administration [17]. On the other hand, there have been cases of GCT recurrence following the cessation of denosumab therapy. Although the previous report showed that the mean time to recurrence was approximately 2 years after surgery [18], there has been no recurrence in the current case 2 years after the operation, suggesting the possibility that TES combined with preoperative denosumab is effective for giant spinal GCT. Furthermore, as the use of denosumab to treat GCT will probably increase, further controlled studies to determine the optimal period to use denosumab without promoting malignant transformation and recurrence are needed.

In conclusion, this case report describes a patient with paravertebral GCT who was successfully treated by preoperative denosumab injection followed by TES.

\section{Abbreviations}

CKD: Chronic kidney disease; CT: Computed tomography; GCT: Giant cell tumor; MRI: Magnetic resonance imaging; PMMA: Polymethylmethacrylate; PTH: Parathyroid hormone; RANKL: Receptor activator of nuclear factor-kappa $\beta$ ligand; TES: Total en bloc spondylectomy

\section{Acknowledgements}

We would like to thank the staff and management at the Department of Orthopaedic Surgery, Graduate School of Medicine Chiba University.

\section{Funding}

All authors received no specific funding for the report.

\section{Availability of data and materials}

The data supporting the conclusions of this article are included within the article.

\section{Authors' contributions}

HK, SO, KI, KA, MI, MN, TU, KF, YS, HirohitoK, TF, KT, and SeO analyzed and interpreted the patient data. $\mathrm{HK}, \mathrm{SO}$, and $\mathrm{SeO}$ performed the surgery and followed up the case. KT, TY, TI, SI, HirotoK, and TT advised of the diagnosis and treatment of the case. $\mathrm{HK}, \mathrm{SO}$, and $\mathrm{SeO}$ were major contributors in writing the manuscript. All authors read and approved the final manuscript.

Ethics approval and consent to participate

Not applicable for case reports.

\section{Consent for publication}

Written informed consent was obtained from the patient for publication of this case report and any accompanying images. A copy of the written consent is available for review by the Editor-in-Chief of this journal.

\section{Competing interests}

The authors declare that they have no competing interests.

\section{Publisher's Note}

Springer Nature remains neutral with regard to jurisdictional claims in published maps and institutional affiliations.

\section{Author details}

'Department of Orthopaedic Surgery, Graduate School of Medicine, Chiba University, 1-8-1, Inohana, Chuo-ku, Chiba 260-8670, Japan. ${ }^{2}$ Department of Orthopaedic Surgery, Saiseikai Narashino Hospital, 1-1-1, Izumicho, Narashino, Chiba 275-8580, Japan. ${ }^{3}$ Department of Orthopedic Surgery, Chiba Cancer Center, 666-2 Nitonacho, Chuo-ku, Chiba 260-8717, Japan. ${ }^{4}$ Department of Musculoskeletal Oncology, National Cancer Center Hospital, 5-1-1, Tsukiji, 
Chuo-ku, Tokyo 104-0045, Japan. ${ }^{5}$ Department of Orthopedic Surgery, Tsukuba University, 1-1-1, Tennodai, Tsukuba, Ibaraki 305-8577, Japan.

Received: 10 August 2018 Accepted: 24 February 2019

Published online: 26 April 2019

\section{References}

1. Harrop JS, Schmidt MH, Boriani S, Shaffrey Cl. Aggressive "benign" primary spine neoplasms: Osteoblastoma, aneurysmal bone cyst, and giant cell tumor. Spine. 2009;34:39-47.

2. Zheng MH, Robbins $\mathrm{P}, \mathrm{Xu}$ J, et al. The histogenesis of giant cell tumour of bone: a model of interaction between neoplastic cells and osteoclasts. Histol Histopathol. 2001;16:297-307.

3. Van Der Heijden L, Dijkstra PDS, Blay JY, Gelderblom H. Giant cell tumour of bone in the denosumab era. Eur J Cancer. 2017:77:75-83.

4. Kroep J, Grimer R, Reichardt P, Rutkowski P, et al. Safety and efficacy of denosumab for adults and skeletally mature adolescents with giant cell tumour of bone: Interim analysis of an open-label, parallel-group, phase 2 study. Lancet Oncol. 2013;14:901-8.

5. Dahlin D. Giant-cell tumor of vertebrae above the sacrum: a review of 31 cases. Cancer. 1977:39:1350-6.

6. Santiago-Dieppa DR, Hwang LS, Bydon A, et al. L4 and L5 spondylectomy for en bloc resection of giant cell tumor and review of the literature. Evid Based Spine Care J. 2014;5:151-7.

7. Kawahara N, Tomita K, Murakami H, et al. Total en bloc spondylectomy of the lower lumbar spine: a surgical techniques of combined posterior and anterior approach. Spine. 2011;36:74-82.

8. Boriani S, Weinstein JN, Biagini R. Primary bone tumors of the spine. Terminology and surgical staging. Spine. 1997;22:1036-44.

9. Clarkson PW, Hurlbert J, Fox R, Zhang H, Lewis S, Riaz S, et al. Surgical management of primary bone tumors of the spine: Validation of an approach to enhance cure and reduce local recurrence. Spine. 2011;36:830-6.

10. Ouyang $H Q$, Jiang $L$, Liu XG, Wei F, Yang SM, Meng N, Jiang P, Yu M, Wu FL, Dang L, Zhou H, Zhang H, Liu ZJ. Recurrence Factors in Giant Cell Tumors of the Spine. Chin Med J. 2017;130:1557-63.

11. Inoue G, Imura T, Miyagi M, Saito W, Tazawa R, Nakazawa T, Takaso M. Total en bloc spondylectomy of the eleventh thoracic vertebra following denosumab therapy for the treatment of a giant cell tumor. Oncol Lett. 2017:14:4005-10.

12. Goldschlager T, Dea N, Boyd M, Reynolds J, Patel S, Rhines LD, Mendel E, Pacheco M, Ramos E, Mattei TA, Fisher CG. Giant cell tumors of the spine: has denosumab changed the treatment paradigm? I Neurosurg Spine. 2015:22:526-33.

13. McClung MR, Lewiecki EM, Cohen SB, Bolognese MA, Woodson GC, Moffett $\mathrm{AH}$, et al. Denosumab in postmenopausal women with low bone mineral density. N Engl J Med. 2006:354:821-31.

14. Thomas D, Henshaw R, Skubitz K, Chawla S, Staddon A, Blay JY, et al. Denosumab in patients with giant-cell tumour of bone: an open-label, phase 2 study. Lancet Oncol. 2010;11:275-80.

15. Salim SA, Nair LR, Thomas L, Garla V, Palabindala V, Agarwal M, Fülöp T. Denosumab-Associated Severe Hypocalcemia in a Patient With Chronic Kidney Disease. Am J Med Sci. 2018;355:506-9.

16. Errani C, Tsukamoto S, Mavrogenis AF. How safe and effective is denosumab for bone giant cell tumour? Int Orthop. 2017;41:2397-400

17. Broehm CJ, Garbrecht EL, Wood J, Bocklage T. Two Cases of Sarcoma Arising in Giant Cell Tumor of Bone Treated with Denosumab. Case Rep Med. 2015;2015:767198.

18. Kajiwara D, Kamoda H, Yonemoto T, Iwata S, Ishii T, Tsukanishi T, Ohtori S, Yamazaki M. Okawa A. Denosumab for Treatment of a Recurrent Cervical Giant-Cell Tumor. Asian Spine J. 2016;10:553-7.

Ready to submit your research? Choose BMC and benefit from:

- fast, convenient online submission

- thorough peer review by experienced researchers in your field

- rapid publication on acceptance

- support for research data, including large and complex data types

- gold Open Access which fosters wider collaboration and increased citations

- maximum visibility for your research: over $100 \mathrm{M}$ website views per year

At $\mathrm{BMC}$, research is always in progress.

Learn more biomedcentral.com/submissions 